Proc. Estonian Acad. Sci. Biol. Ecol., 2003, 52, 3, 332-345

\title{
The modelling of ecosystem processes in the Gulf of Finland
}

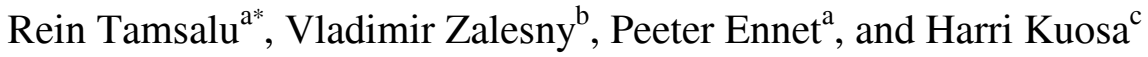 \\ ${ }^{a}$ Estonian Marine Institute, Mäealuse 10a, 12618 Tallinn, Estonia \\ ${ }^{\mathrm{b}}$ Institute of Numerical Mathematics, Olympic village 6-139, 117602 Moscow, Russia \\ c Finnish Institute of Marine Research, P.O. Box 33, FIN-00931 Helsinki, Finland; \\ Harri.Kuosa@fimr.fi
}

Received 16 December 2002

\begin{abstract}
The aim of this work was to introduce the last version of the hydrodynamic-ecosystem model FinEst and to supplement this model to enable its easy application for local areas. Complications in the case of local areas appear in the treatment of initial and open boundary conditions. This paper demonstrates how to handle the open boundaries and the initial data using a multi-step scheme of calculations in the Baltic Sea. First the model was applied for the entire Baltic Sea. Then the results of these calculations were used for the Gulf of Finland (GOF). Finally, calculations for some local areas in the GOF were made using the initial and open boundary conditions from the results of the GOF calculations.
\end{abstract}

Key words: ecosystem, modelling, plankton.

\section{INTRODUCTION}

All ecosystems consist of abiotic and biotic factors and their interactions. Abiotic factors are both physical and chemical environmental factors. In the present water ecosystem model family a hydrodynamic model describes physical factors. Chemical factors are described by a nutrient recycling model and a separate sediment model. Biotic factors are factors of biological nature, such as the availability of food, competition between species, predator and prey relationships, etc. The simplest ecosystem model is based on the functional roles of the organisms, i.e. it may be constructed by using one producer group, its resources, and one consumer group. However, because of the complexity of the water ecosystems, instead of one triplet plankton community model, more

*Corresponding author, bill@sea.ee 
components are needed to answer questions concerning the response of biota to both natural and man-made changes in environmental forcing factors.

The splitting-up method is used to calculate the hydrodynamic and ecological equations (Zalesny, 1996; Zalesny \& Tamsalu, 2000; Ennet et al., 2000). The multi-step scheme was assigned to apply the hydrodynamic-ecosystem model for some selected local areas in the Gulf of Finland (GOF). First the model was applied for the whole Baltic Sea. Then the results of these calculations were used for the GOF calculations. Finally, calculations for some small local areas in the GOF were made (grid step was $1 / 6 \mathrm{~nm}$ ) with the initial and open boundary conditions derived from the results of the GOF calculations (Fig. 1). In the small-scale calculations a nonhydrostatic model was used. Using this multi-step calculation scheme the end-user can easily analyse the impact of different effects (e.g. coastal pollution conditions) in some local area using previously prepared open boundary and initial conditions.

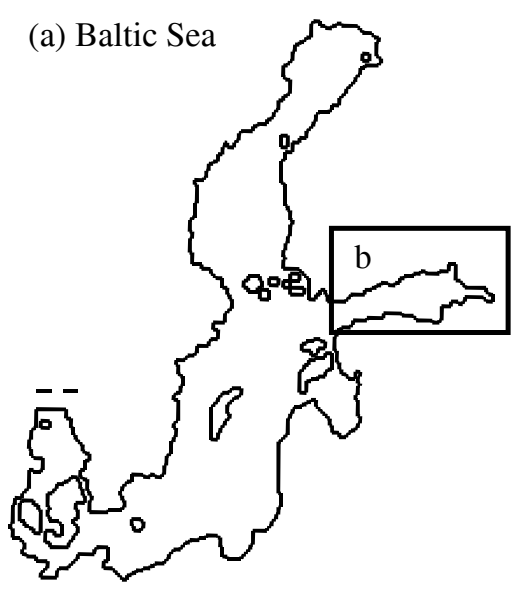

- - - - Open boundary

(b) Gulf of Finland

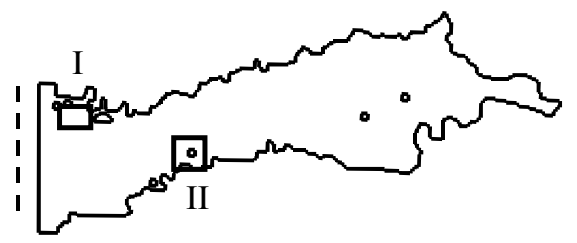

I-II Local areas, selected by end-user

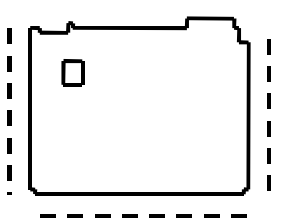

I

Tvärminne

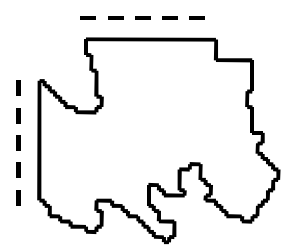

II

Fig. 1. Coupling of areas with different grid resolution.

\section{MODEL DESCRIPTION}

The hydrodynamic-ecological model is based on the 3D free-surface primitive equation system. The governing equations of the model are the momentum equation for velocity vector $U$ with components $u, v$, and $w$ under Boussinesq approximation; transport-diffusion equation for temperature $T$, salinity $S$, turbulent kinetic energy $k$, dissipation rate $\varepsilon$, and biochemical tracers $C_{i}$; the continuity equation for incompressible fluid and state equation: 


$$
\begin{gathered}
{\left[\frac{d}{d t}-\Lambda\right] U+2 \Omega \times U=-\operatorname{grad}\left(\frac{p}{\rho_{0}}-b z\right),} \\
{\left[\frac{d}{d t}-\Lambda\right] c=F_{c},} \\
\operatorname{div} U=0, \\
b=f(T, S) .
\end{gathered}
$$

Here

$$
\begin{aligned}
& U=\left(\begin{array}{lll}
u & & \\
& v & \\
& & w
\end{array}\right) c=\left(\begin{array}{lllll}
T & & & & \\
& S & & & \\
& & k & & \\
& & \varepsilon & \\
& & & C_{i}
\end{array}\right) F_{c}=\left(\begin{array}{lllll}
0 & & & & \\
& 0 & & & \\
& & F^{k} & & \\
& & F^{\varepsilon} & \\
& & & F_{i}^{E c o}
\end{array}\right), \\
& \frac{d}{d t}=\frac{\partial}{\partial t}+u \frac{\partial}{\partial x}+v \frac{\partial}{\partial y}+w \frac{\partial}{\partial z} \quad \Lambda=\frac{\partial}{\partial x} \mu \frac{\partial}{\partial x}+\frac{\partial}{\partial y} \mu \frac{\partial}{\partial y}+\frac{\partial}{\partial z} v \frac{\partial}{\partial z}, \\
& F^{k}=\gamma_{1} \frac{k^{2}}{\varepsilon}-\varepsilon, \quad F^{\varepsilon}=c_{1} \gamma_{2} k-c_{2} \frac{\varepsilon^{2}}{k}, \\
& \gamma_{1}=c_{\mu}\left[\left(\frac{\partial u}{\partial z}\right)^{2}+\left(\frac{\partial v}{\partial z}\right)^{2}-\frac{1}{\sigma_{T}} \frac{\partial b}{\partial z}\right] \gamma_{2}=c_{\mu}\left[\left(\frac{\partial u}{\partial z}\right)^{2}+\left(\frac{\partial v}{\partial z}\right)^{2}-\frac{c_{3}}{\sigma_{T}} \frac{\partial b}{\partial z}\right],
\end{aligned}
$$

$v=c_{\mu} k^{2} \varepsilon^{-1}$ is vertical turbulent diffusion coefficient, $\mu$ is horizontal turbulent diffusion coefficient, $\Omega$ is the angular speed of the rotation of the Earth, $z$ is downward vertical coordinate, $p$ is pressure, $b=g\left(\rho-\rho_{0}\right) / \rho_{0}$ is buoyancy, $\rho$ is density, $\rho_{0}$ is reference density, $g$ is the gravitational acceleration, $F^{e c o}$ describes biochemical processes. $\sigma_{T}=f(R i)$, where $R i$ is the Richardson number and $c_{\mu}, c_{1}, c_{2}$, and $c_{3}$ are constants. The $k-\varepsilon$ model for turbulent mixing is described by Burchard \& Baumert (1995).

\section{PHYSICAL PROCESSES CALCULATION}

In the first splitting step the transport-diffusion of momentum, temperature, salinity, turbulent kinetic energy, turbulent dissipation rate, and bio-chemical tracers are solved: 


$$
\left[\frac{d}{d t}-\Lambda\right] \varphi=0, \quad \varphi=\left(\begin{array}{ll}
U & \\
& c
\end{array}\right) .
$$

Here $\operatorname{div} U=0$.

The initial conditions for solving (1)-(4) will be taken from previous splitting step calculations.

In the second splitting step the inertial oscillation of momentum is solved:

$$
\frac{\partial U}{\partial t}+2 \Omega \times U=0 .
$$

Here in general $\operatorname{div} U \neq 0$.

In the third splitting step the adaption of velocity and pressure fields is solved. Following Marshall et al. (1997) the pressure $p$ is presented as the sum of hydrostatic $\hat{p}$ and nonhydrostatic $\tilde{p}$ part, which are solved in different splitting steps.

The following equations will be written for the hydrostatic regime:

$$
\frac{\partial}{\partial t}\left(\begin{array}{ll}
u & \\
& v
\end{array}\right)+\frac{1}{\rho_{0}}\left(\begin{array}{ll}
\frac{\partial \hat{p}}{\partial x} & \\
& \frac{\partial \hat{p}}{\partial y}
\end{array}\right)=0, \quad \frac{1}{\rho_{0}} \frac{\partial \hat{p}}{\partial z}=b .
$$

In this splitting step in general $\operatorname{div} U \neq 0$.

For the nonhydrostatic regime we have the following equation:

$$
\frac{\partial U}{\partial t}+\operatorname{grad}\left(\frac{\tilde{p}}{\rho_{0}}\right)=0 .
$$

Here $\operatorname{div} U=0$.

Taking the divergence in finite difference by time Eq. (8) will become the equation for the nonhydrostatic pressure $\tilde{p}$ :

$$
\Delta \tilde{p}=\frac{\rho_{0}}{\tau \operatorname{div} U^{0}} .
$$

On the boundary $\partial \tilde{p} / \partial n=0$. Here $\tau$ is the time step and $\operatorname{div} U^{0}$ is calculated from the previous splitting step.

In the last splitting step the turbulent energy production and dissipation rate are solved by the following equations: 


$$
\frac{\partial}{\partial t}\left(\begin{array}{ll}
k & \\
& \varepsilon
\end{array}\right)=\left(\begin{array}{ll}
\gamma_{1} \frac{k_{2}}{\varepsilon}-\varepsilon & \\
& c_{1} \gamma_{2} k-c_{2} \frac{\varepsilon^{2}}{k}
\end{array}\right) .
$$

Equation (10) has analytical solutions, which are given in Burchard \& Baumert (1995).

\section{ECOLOGICAL PROCESSES CALCULATION}

We start from a simple model in which the plankton community's food web is formed by one autotrophic $(A)$ and one heterotrophic $(H)$ component and heterotrophic bacterioplankton $(B)$. This plankton community forms the triplet structure with two preys (autotrophic component and bacterioplankton) and one predator (heterotrophic component). Dead organisms form detritus $(D)$. There are two energy flows to the plankton community. The first one is the uptake of dissolved inorganic nutrients $(D I N)$ by phytoplankton and it is directed from the autotrophy toward heterotrophy through grazing. The other is the uptake of dissolved organic $(D O N)$ and inorganic nutrients $(D I N)$ by bacterioplankton and it is directed from bacterioplankton towards heterotrophy through predation. Energy is lost through autotrophy exudation, mortality, and respiration; heterotrophy excretion, mortality, and respiration; bacterioplankton excretion and respiration; and detritus decay. As we see there are thirteen $\left(N_{p}=13\right)$ biochemical processes.

To solve the problem we use the process oriented calculation method, extracting $N_{s}\left(i_{s}=1, N s\right)$ by splitting steps, which are described by $N_{p}\left(i_{p}=1, N p\right)$ basic biochemical processes. The process oriented ecosystem calculations form the following equation systems:

$$
\begin{aligned}
& \text { for uptake }\left(i_{s}=i_{p}=1,2\right) \\
& \frac{d A}{d t}=\operatorname{uptake}(D I N), \\
& \frac{d D I N}{d t}=-c n * \operatorname{uptake}(D I N),
\end{aligned}
$$

$$
\begin{aligned}
& \frac{d B}{d t}=\operatorname{uptake}(D I N+D O N) \\
& \frac{d(D I N+D O N)}{d t}=-c n * \operatorname{uptake}(D I N+D O N)
\end{aligned}
$$

for grazing/predation $\left(i_{s}=i_{p}=3,4\right)$ 


$$
\begin{aligned}
& \frac{d H}{d t}=\beta * \text { grazing }(A), \\
& \frac{d A}{d t}=- \text { grazing, } \\
& \frac{d D I N}{d t}=c n(1-\beta) \text { grazing, } \\
& \frac{d H}{d t}=\beta * \text { predation }(B), \\
& \frac{d B}{d t}=- \text { predation }(B), \\
& \frac{d D I N}{d t}=\text { cn }(1-\beta) \text { predation; }
\end{aligned}
$$

for exudation/excretion $\left(i_{s}=i_{p}=5,6,7\right)$

$$
\begin{aligned}
& \frac{d A}{d t}=- \text { exudation }(A), \\
& \frac{d D O N}{d t}=c n * \text { exudation }(A), \\
& \frac{d H}{d t}=-\operatorname{excretion}(H), \\
& \frac{d D O N}{d t}=c n * \operatorname{excretion}(A), \\
& \frac{d B}{d t}=-\operatorname{excretion}(B), \\
& \frac{d D O N}{d t}=\operatorname{cn} * \operatorname{excretion}(B) ;
\end{aligned}
$$

for mortality $\left(i_{s}=i_{p}=8,9\right)$

$$
\begin{aligned}
& \frac{d A}{d t}=-\operatorname{mortality}(A), \\
& \frac{d D}{d t}=\operatorname{mortality}(A),
\end{aligned}
$$




$$
\begin{aligned}
& \frac{d H}{d t}=-\operatorname{mortality}(H), \\
& \frac{d D}{d t}=\text { mortality }(A) ; \\
& \text { for decay }\left(i_{s}=i_{p}=10\right) \\
& \frac{d D}{d t}=-\operatorname{decay}(D), \\
& \frac{d D I N}{d t}=\operatorname{cn} * \operatorname{decay}(D) ;
\end{aligned}
$$

and for respiration $\left(i_{s}=i_{p}=11,12,13\right)$

$$
\begin{aligned}
& \frac{d A}{d t}=- \text { respiration }(A), \\
& \frac{d D I C}{d t}=c c * \text { respiration }(A), \\
& \frac{d H}{d t}=- \text { respiration }(H), \\
& \frac{d D I C}{d t}=c c * \text { respiration }(H), \\
& \frac{d B}{d t}=-r e s p i r a t i o n(B), \\
& \frac{d D I C}{d t}=c c * \text { respiration }(B) .
\end{aligned}
$$

The first four equation systems of (11)-(23) describe resource consumption processes where the plankton biomass is increasing and the nutrient concentration is decreasing. The resource consumption processes are parameterized by the Michaelis-Menten nonlinear kinetics in the following form:

$$
\begin{gathered}
\operatorname{uptake}(D I N)=G A * D I N * A, \quad G A=f_{A}(T) * f(I) \frac{G a(\max )}{c a n+D I N}, \\
\operatorname{uptake}(D I N+D O N)=G B *(D I N+D O N) * B \\
G B=f_{B}(T) \frac{G b(\max )}{c a n+D I N+D O N},
\end{gathered}
$$




$$
\begin{aligned}
& \operatorname{grazing}(A)=G G * A * H, \quad G G=f_{H}(T) \frac{G h(\max )}{c a z+A}, \\
& \operatorname{predation}(B)=G P * B * H, \quad G P=f_{H}(T) \frac{G h(\max )}{c a z+B},
\end{aligned}
$$

where $G a(\max )$ is the maximum autotrophic growth rate, $G b(\max )$ is the maximum bacterioplankton growth rate, $G h(\max )$ is the maximum heterotrophic growth rate, can is the half-saturation constant for the nitrogen uptake process, $c a z$ is the half-saturation constant for heterotrophic growth, $f_{A}(T), f_{B}(T)$, $f_{H}(T)$ are temperature limitation functions and $f(I)$ is the light limitation function.

Using (24)-(27) we see that the resource consumption equations (11)-(14) are described in the similar form:

$$
\frac{d X}{d t}=c x * G X * X * Y, \quad \frac{d Y}{d t}=-c y * G X * X * Y,
$$

where $X$ is the nutrient concentration or prey biomass, $Y$ is the primary producer or predator biomass, $G X * X$ is the process rate, and $c x$ and $c y$ are constants.

The system (28) has the local conservation law for this resource consumption process:

$$
c y * X+c x * Y=\text { const }=c y * X^{0}+c x * Y^{0},
$$

where $X^{0}$ and $Y^{0}$ are initial conditions and will be calculated from the previous splitting step results.

With replacement $Z=X / Y$ it follows that the two equations (28) condense into only one:

$$
\frac{d Z}{d t}+G X\left(c y * X^{0}+c x * Y^{0}\right) Z=0 .
$$

Equation (30) has an analytical solution, which gives by using Eq. (29) the following relations for calculating $X$ and $Y$ during the resource consumption process:

$$
\begin{aligned}
& X=X^{0} \frac{c y * X^{0}+c x * Y^{0}}{c y * X^{0}+c x^{*} Y^{0} \exp \left[-G X\left(c y * X^{0}+c x^{*} Y^{0}\right) \tau\right]}, \\
& Y=Y^{0}-\frac{c x}{c y}\left(X-X^{0}\right) .
\end{aligned}
$$

Here $\tau$ is the time step. 
The last nine-equation system of (13)-(22) describes the plankton loss processes in which the plankton biomass is decreasing and the nutrient concentration is increasing. The plankton loss processes are parameterized by the linear kinetics in the following form:

$$
\begin{aligned}
& \text { exudation }(A)=D_{E X U}(\max ) * f(T) * A, \\
& \operatorname{excretion}\left(\frac{H}{B}\right)=D_{E X C}(\max ) * f(T) *\left(\frac{H}{B}\right), \\
& \operatorname{mortality}\left(\frac{A}{H}\right)=D_{M O R}(\max ) * f(T) *\left(\frac{A}{H}\right), \\
& \operatorname{decay}(D)=D_{D A C}(\max ) * f(T) * D,
\end{aligned}
$$

where $D_{E X U}(\max )$ is the maximum exudation rate; $D_{E X C}(\max )$ is the maximum excretion rate; $D_{M O R}(\max )$ is the maximum mortality rate; $D_{D E C}(\max )$ is the maximum detritus decay rate; and $f(T)$ is the temperature limitation function.

Using Eq. (31) all loss processes (15)-(23) can be described in a similar form:

$$
\frac{d X}{d t}=-D X * X, \quad \frac{d Y}{d t}=c x * D X * X,
$$

which includes the local conservation law and has during one of the loss process the following analytical solutions:

$$
X=X^{0} \exp \left(-D X^{*} \tau\right), \quad Y=Y^{0}+c x\left(X^{0}-X\right) .
$$

To answer concrete questions concerning the response of nature to both natural and man-made changes in environmental forcing factors and loading, more complicated structures (multi-triplet systems) are needed.

Aquatic ecosystem research changed fundamentally during the 1980s when the size-dependent structure was first used for the description of the plankton community's food web. Thus, it became possible to take into account almost the whole spectrum of the plankton community using only four or five size-classes. In our conception the size-dependent plankton community formed $N_{t r}$ triplet structure.

The four-triplet plankton community model is described by Moloney et al. (1991) and Tamsalu \& Ennet (1995). The autotrophic and heterotrophic continuums consist of organisms in size ranges from 0.2 to $250 \mu \mathrm{m} E S D$ (equivalent spherical diameter) and 2 to $1250 \mu \mathrm{m} E S D$, respectively. The bacterioplankton $(B)$ size range is from 0.2 to $2 \mu \mathrm{m} E S D$.

In the four size-classes model autotrophs are divided into netphytoplankton $\left(A_{1}\right)$, nanophytoplankton $\left(A_{2}\right)$, phytoflagellates $\left(A_{3}\right)$, and picophytoplankton $\left(A_{4}\right)$; and heterotrophs into mesozooplankton $\left(H_{1}\right)$, microzooplankton $\left(H_{2}\right)$, nanozooplankton $\left(H_{3}\right)$, zooflagellates $\left(H_{4}\right)$, plus bacterioplankton $(B)$. 


\section{NUMERICAL RESULTS}

One of the most complicated problems in coastal area modelling is handling open boundaries and initial conditions. Setting of open boundary conditions and initial conditions has significant influence on the both calculation results of the hydrodynamic and the ecosystem model. Here we used the multi-step calculation scheme where the open boundary and initial conditions for the zoom area were set from previous results. To prepare the required input data for the selected zoom area (bottom relief file with a smaller grid step, locations of external forcing points in new grid co-ordinates, etc.) we developed software to create these data files automatically. It enables the end-user to easily apply the model for different local areas.

The modelled spring phytoplankton succession follows the pattern typical of the Baltic Sea. It starts from southern areas early in the season, followed by successive blooms in the open Baltic, in the Gulf of Finland, and the Bothnian Sea (see: alg@line). The biomass level of spring bloom depends largely on the initial values of nutrients, and therefore there is no bloom in the northernmost parts of the Bothnian Sea. The timing of the spring bloom is not realistic, but appears to be somewhat delayed (Figs. 2, 3, and 4). This phenomenon depends mainly on the growth of netphytoplankton $(>20 \mu \mathrm{m})$ in the model. To obtain more realistic model results better knowledge is required on the actual growth during spring, which includes light adaptation, temperature effects, and other physiological responses of spring species to the environment.

Summer biomass values of phytoplankton were clearly overestimated in the model runs (Fig. 4). This biomass was calculated as chlorophyll $a$ because the available monitoring data sets list only chlorophyll $a$. Chlorophyll $a$ is a parameter with a variable link to phytoplankton carbon values (e.g. Kuosa et al., 1997). An important feature of the model is that calculated values and actual data have a relatively stable ratio, which clearly points at a good fit on the general characters

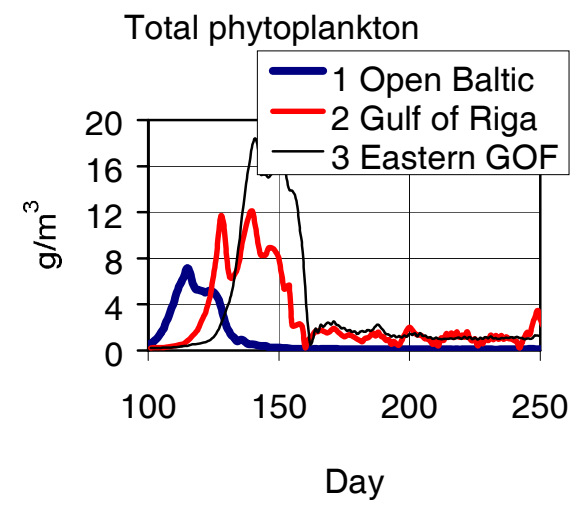

Bacterioplankton

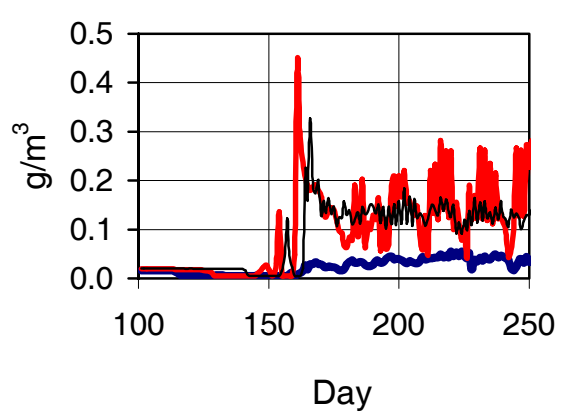

Fig. 2. Calculated succession of total phytoplankton and bacterioplankton in different locations. 

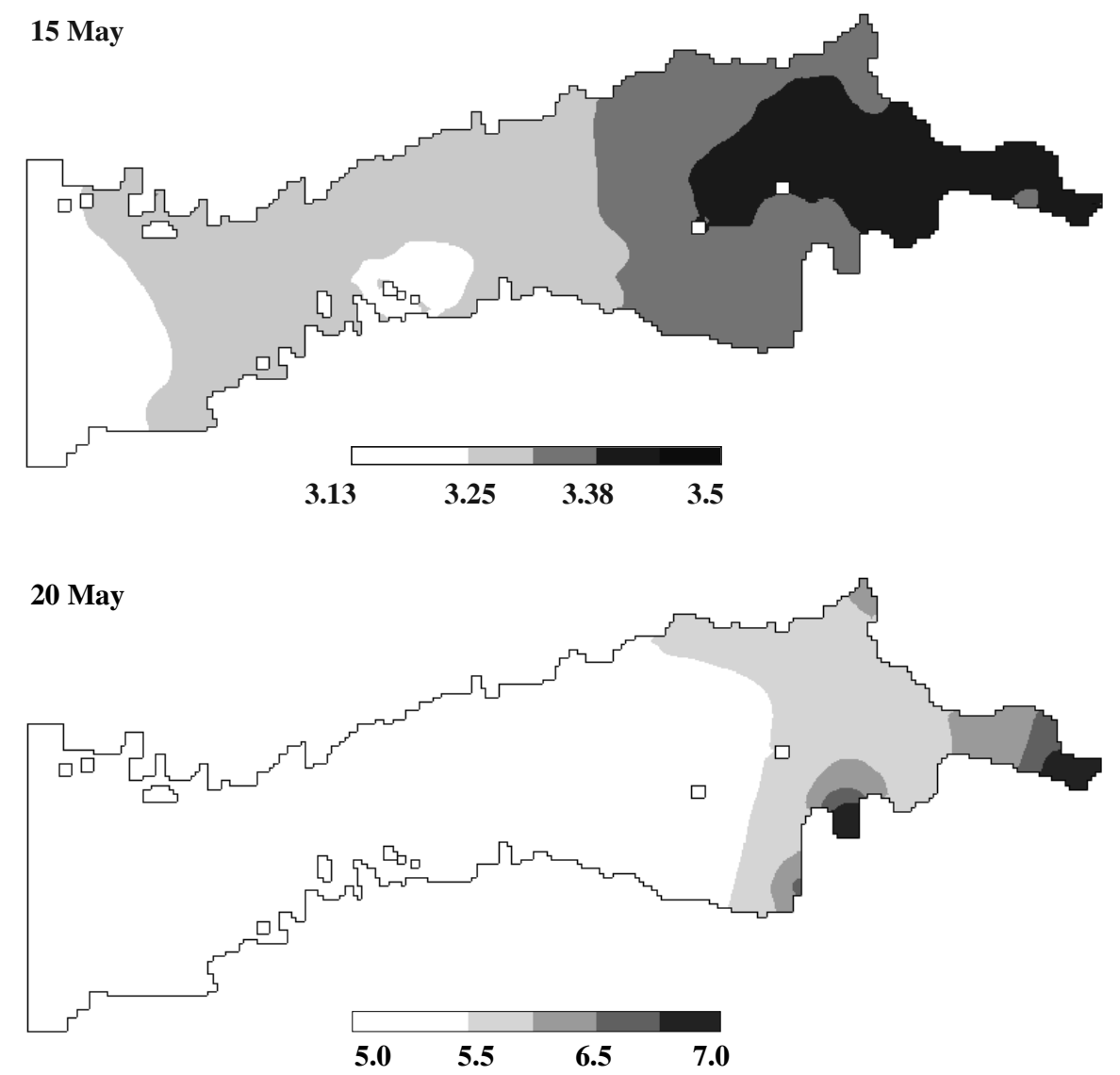

Fig. 3. Calculated total phytoplankton distribution in the Gulf of Finland, g/m $\mathrm{m}^{3}$.
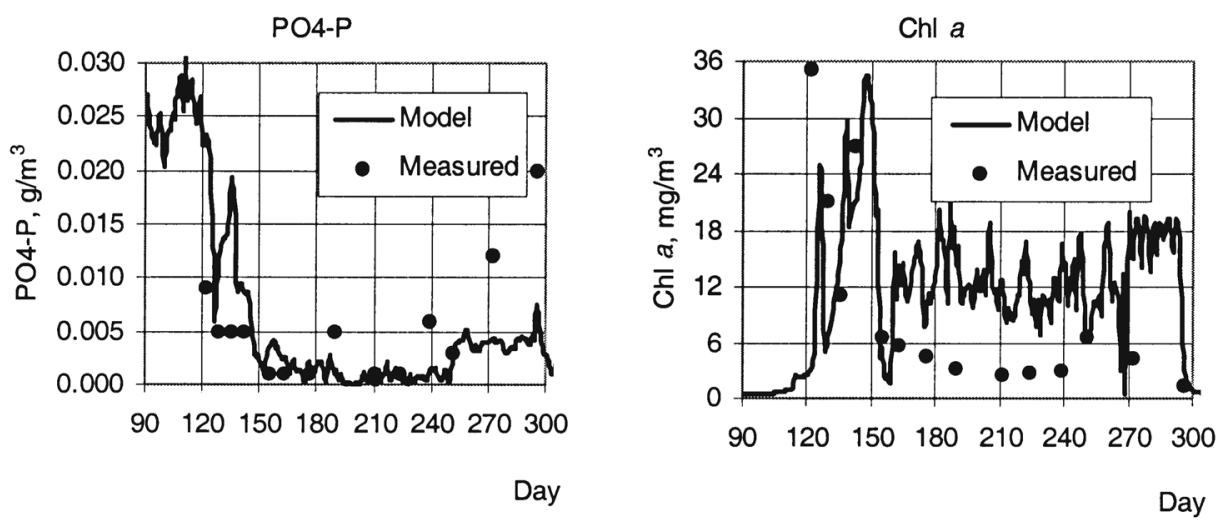

Fig. 4. Comparison of model local area calculation results with Tvärminne data, 1995. 
(a)

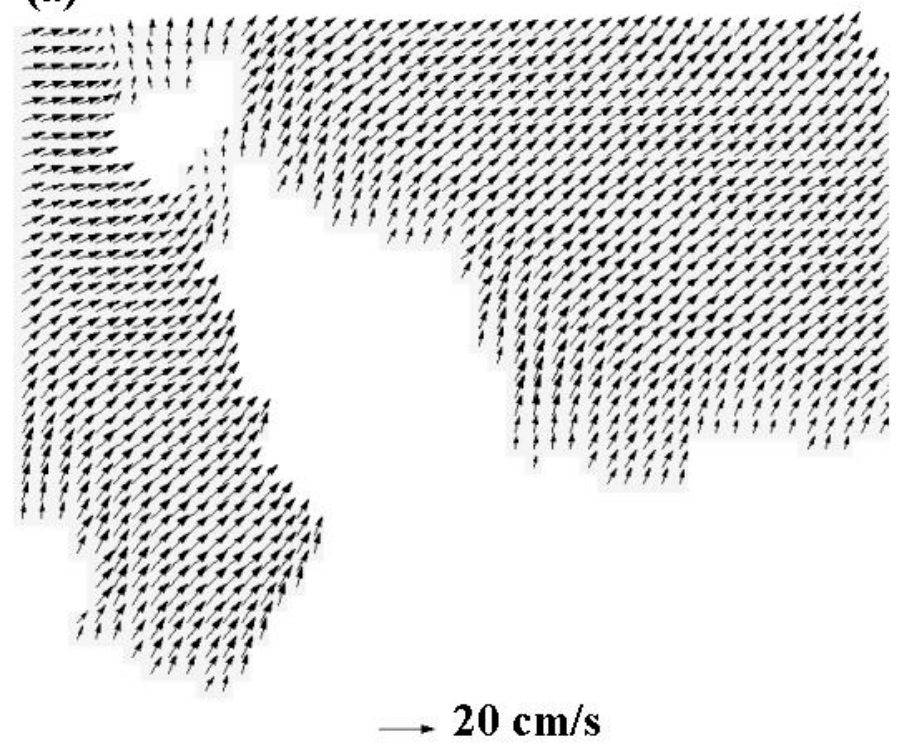

(b)

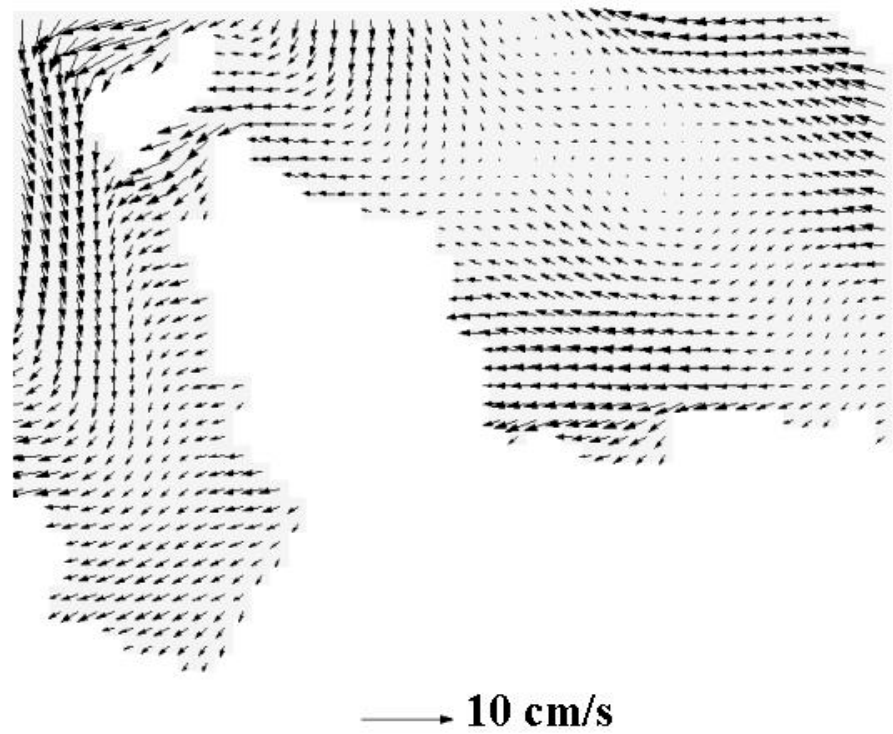

Fig. 5. Calculated currents in Tallinn Bay, wind SSW, a - surface, b - bottom. 
of biomass variability. The ratio of phytoplankton $\mathrm{Chl} a$ and $\mathrm{C}$ depends on the species composition, light adaptation, and several other factors, and it is rather futile to try to fit model results exactly to monitoring results before we know what is behind the discrepancy. One possible explanation is the large share of mixotrophic species during summer. These species get part of their energy from bacteria and small phytoplankton, and thus their energy requirement from primary production is lower compared to e.g. strictly autotrophic spring bloom species.

A specific feature of the present model is its capability to mimic heterotrophic succession. The succession shows low values during the cold-water period and generally high values and high variability during warm water. The mean value during summer depends on the available inorganic and organic nutrients, and the variability mainly on the high predation pressure from rapidly growing heterotrophic nanoflagellates, leading to intense predator-prey cycles. The activity of bacteria during the cold period still awaits for better data sets as it is probable that some bacteria may actually grow at quite high rates at near zero temperatures, but that then the quality of the organic carbon source is a more important limiting factor than during summer.

The physical factors (sea water temperature, salinity, currents, etc.) have an essential effect on plankton productivity. To illustrate the variation of physical circumstances in the coastal waters Fig. 5 presents the calculated currents in Tallinn Bay. It can be easily imagined how important it is to consider in calculations the boundary effects.

\section{CONCLUSIONS}

To summarize we can say that the treatment of open boundaries and initial conditions is a complicated problem for the end-user. Setting open boundary and initial conditions is of special significance in coastal region modelling where the calculation area is relatively small. In this work we used the multi-step calculation scheme where the open boundary and initial condition values were set from previous results. Comparison of the model results with measured data in Tvärminne shows that the use of this multi-step method for the local area calculations is acceptable. In general the model results were reasonably realistic, giving typical patterns of plankton succession in the Baltic Sea.

\section{REFERENCES}

Burchard, H. \& Baumert, H. 1995. On the performance of a mixed-layer model based on the k- $\varepsilon$ turbulence closure. J. Geophys. Res., 100, 8523-8540.

Ennet, P., Kuosa, H. \& Tamsalu, R. 2000. The influence of upwelling and entrainment on algal bloom in the Baltic Sea. J. Mar. Syst., 25, 359-367.

Kuosa, H., Autio, R., Kuuppo, P., Setälä, O. \& Tanskanen, S. 1997. Nitrogen, silicon and zooplankton controlling the Baltic spring bloom: an experimental study. Estuar. Coast. Shelf Sci., 45, 813-821. 
Moloney, C. \& Field, J. 1991. The size-dependent dynamics of plankton food webs. I. A simulation model of carbon and nitrogen flows. J. Plankton Res., 13, 1003-1038.

Marshall, J., Hill, C., Perelman, L. \& Adcroft, A. 1997. Hydrostatic, quasi-hydrostatic and nonhydrostatic ocean modelling. J. Geophys. Res., 102, 5733-5752.

Tamsalu, R. \& Ennet, P. 1995. Ecosystem modelling in the Gulf of Finland. II. The aquatic ecosystem Model FINEST. Estuar. Coast. Shelf Sci., 41, 429-458.

Zalesny, V. B. 1996. Numerical simulation and analysis of the sensitivity of large-scale ocean dynamics. Russ. J. Numer. Anal. Math. Modelling. V. 11(6), 421-443.

Zalesny, V. B. \& Tamsalu, R. 2000. Numerical analysis of the marine dynamics. In Proc. Intern. Conf. "Numerical mathematics and mathematical modelling", pp. 110-124. INM Ras, Moscow.

\section{Soome lahe ökosüsteemi protsesside modelleerimine}

\section{Rein Tamsalu, Vladimir Zalesny, Peeter Ennet ja Harri Kuosa}

Töö eesmärk oli veeökosüsteemi mudeli FinEst viimase versiooni tutvustamine. Peatähelepanu oli pööratud mudeli kohaldamisele suhteliselt väikeste rannikupiirkondade puhul. Selliste piirkondade arvutamisel tekivad sageli raskused nii lähteandmete kui ka avatud piiril antavate tingimuste määramisel. Läänemere (Soome lahe) näite põhjal on selgitatud, kuidas lokaalsete arvutuspiirkondade lähteandmeid ning avatud piire saadakse numbrilise mudeli järkjärgulise lahendamise teel. 